\title{
Pelatihan Kemampuan Komunikasi Bahasa Inggris Sebagai Kesiapan Ekonomi Bagi Siswa PIK R Di SMP Muhammadiyah I Rawabening
}

\author{
Zulaikah1, Hatuti Retno K.2 , Mursilah³ \\ STKIP Nurul Huda OKU Timur \\ E-mail: ${ }^{1}$ zulaikah@stkipnurulhuda.ac.id, ${ }^{2}$ retno@stkipnurulhuda.ac.id, \\ ${ }^{3}$ mursilah_mursilah@yahoo.com
}

\begin{abstract}
This activities starts from the PIK $R$ group which did not create activities mainly related to life skills for economic preparation for adolescents in planning a happy and prosperous family life. Lack of knowledge, attitudes, behavior of adolescents about life skills (English language ability) to be practiced so that growth and development to the fullest in order to realize the generation of planning. the low knowledge of family life readiness especially economic readiness, the low Life Skill especially English language skills is an important issue being faced. The solution offered from these problems is continuous training on Life Skills and English communication skills for PIK $R$ students. The method used is the silent way, with consonant vocal recitation correctly. The results of this devotion were very high enthusiasm from the participants with their enthusiasm for learning, designing creativity and becoming a problem solver for their educational problems. Characterized by the increased ability of English communication, especially in terms of vocabularies about economic learning.
\end{abstract}

Keywords: Communication skills in English, Economic readiness

\section{Pendahuluan}

Masa remaja adalah masa peralihan atau masa transisi dari anak-anak ke dewasa. ${ }^{1}$ Kehidupan remaja merupakan kehidupan yang sangat menentukan kehidupan selanjutnya. Wadah organisasi remaja dalam mewujudkan remaja sehat, cerdas dan ceria adalah Pusat Informasi Konseling Remaja atau biasa disingkat PIK R. PIK R adalah suatu wadah kegiatan program penyiapan kehidupan berkeluarga bagi remaja yang dikelola dari, oleh dan untuk remaja guna memberikan pelayanan informasi

${ }^{1}$ E.B Hurlock, Psikologi perkembangan, (Jakarta: Erlangga 1993) 
dan konseling tentang perencanaan kehidupan berkeluarga bagi remaja serta kegiatan-kegiatan penunjang lainnya. ${ }^{2}$ Menujuk pada permasalahan remaja seperti pernikahan dini, seks bebas dan Napza maka melalui PIK R dengan program Generasi Berencana (GenRe) yang salah satunya adalah keterampilan hidup (Life Skill) yaitu pendidikan non formal yang berberikan keterampilan non formal, sosial, intelektual/akademis, dan vokasional untuk bekerja secara mandiri. ${ }^{3}$ Ketrampilan hidup yang dikembangkan dalam program penyiapan kehidupan berkeluarga bagi remajadi SMP Rawabening lebih ditekankan pada ketrampilan kemampuan berbahasa inggris.

Di era globalisasi sekarang ini, semakin banyak perkembangan yang terjadi di negeri ini. Mulai dari perdagangan bebas, semakin banyaknya berdiri perusahaan-perusahaan asing di indonesia sehingga penggunaan bahasa internasinal seperti bahasa inggris sudah sangat tersebar luas, tentunya untuk para calon entrepreneur dan pencari kerja sudah menjadi suatu keharusan untuk bisa menguasai bahasa inggris agar bisa mengikuti perkembangan jaman di era globalisasi ini.

Chaer mengemukakan adanya istilah bahasa target yang merupakan bahasa yang sedang dipelajari dan ingin dikuasai. ${ }^{4}$ Kemampuan berbahasa inggris bagi siswa siswi PIK $\mathrm{R}$ di SMP Muhammadiyah Rawabening diharapkan dapat menjadi bekal kesiapan secara ekonomi dalam kehidupan berumah tangga. Masalah perekonomian keluarga adalah salah satu sumber disorganisasi dalam keluarga. Umumnya masalah keluarga dari hal-hal kecil sampai pada perceraian disebabkan oleh masalah ekonomi keluarga. Jenis kebutuhan keluarga diantaranya kebutuhan primer misal sandang, pangan, papan, kebutuhan sekunder misalnya rekreasi, kesehatan dan pendidikan, serta kebutuhan tersier misanya mobil, apartemen dan lain-lain.

\footnotetext{
2016)

${ }^{2}$ Masri Muadz, dk. Penyiapan Kehidupan Berkeluarga bagi Remaja,( Jakarta: BKKBN,

3 Undang-undang Sistem Pendidikan Nasional No 20 Tahun 2003

${ }^{4}$ Abdul Chaer, Pengantar Semantik Bahasa Indonesia. (Jakarta: Rineka Cipta 2009), 37.
} 
Kebutuhan primer, sekunder, dan tersier keluarga adalah fakta yang tidak bisa dipungkiri dan setiap keluarga memerlukannya. Kebutuhan keluarga apabila tidak dipenuhi akan menjadi sumber masalah dalam keluarga. Maka dari itu sebelum memasuki kehidupan berkeluarga perlu kesiapan untuk memenuhi kebutuhan-kebutuhan primer, sekunder, dan tersier.

Program penyiapan kehidupan berkeluarga bagi remaja menganjurkan setiap remaja mempersiapkan diri secara ekonomi sebelum memasuki kehidupan rumah tangga. Salah satu cara penyiapan diri tersebut adalah dengan melatih diri untuk kemampuan berbahasa inggris sebagai kesiapan ekonomi bagi calon pasangan atau calon suami istri. Permasalahan yang ditemukan adalah Kurangnya pemahaman dan pengetahuan remaja terhadap program GenRe terutama life skill, kemampuan bahasa Inggris sebagai kesiapan ekonomi menuju keluarga kecil bahagia sejahtera, Rendahnya dukungan dana kegiatan life skill kemampuan berkomunikasi dengan bahasa Inggris bagi PIK R, serta Perlunya pembinaan life skill, kemampuan bahasa Inggris secara berkelanjutan dari instansi terkait untuk mendukung kesiapan ekonomi remaja dalam penyiapan kehidupan berkeluarga.

\section{Metode}

Silent Way merupakan metode yang dikembangkan oleh Caleb Gattegno, yang dilandasi dengan adanya keyakinan bahwa siswa hendaknya belajar secara independen dan tidak bergantung kepada guru. ${ }^{5}$ Gattegno mengemukakan bahwa siswa yang akan belajar itu lebih baik apabila mereka mengembangkan tanggungjawab personal atas pembelajarannya. Jadi, untuk realisasi pembelajaran, guru tetap diam.

5 Caleb Gattegno, Teaching Foreign Language in Schools The Silent Way, 2 nd ed.(NewYork : Educational Solutions, 1972), 80. 
Belajar dipandang lebih utama dibandingkan dengan mengajar. Para siswa didorong untuk bekerjasama antara satu dengan yang lain untuk memikirkan atau memahami makna. Para siswa diperkenalkan dengan materi baru dengan menggunakan tongkat Cuisinare (tongkat-tongkat kecil berwarna dengan ukuran panjang yang beragam) dan serangkaian peta dinding (wall chart). Setelah guru memperkenalkan materi itu, tinggal para siswa dipersilahkan untuk menentukan apa yang akan mereka pelajari dan bekerja secara independen untuk mencapai tujuan akademis mereka.

Gattegno mengusulkan artificial approach yang didasarkan pada prinsip bahwa pembelajaran yang berhasil melibatkan sebuah komitmen diri pada pemerolehan bahasa melalui kesadaran dan uji coba aktif. Penekanan Gattegno yang berulang-ulang pada lebih pentingnya pembelajaran daripada pengajaran, menempatkan komitmen dan prioritas diri pembelajar sebagai fokus. Diri yang dimaksud di sini terdiri atas dua sistem, yaitu sistem pembelajaran dan sistem pemerolehan.

Sistem pembelajaran diaktifkan oleh kesadaran intelegensi. Silence dianggap sebagai cara yang terbaik untuk pembelajaran, karena dengan silence para pembelajar berkonsentrasi pada tugas yang diselesaikan dan cara-cara potensial untuk penyelesaiannya. Silence, yang menghindari pengulangan, menjadi alat bantu bagi kesadaran, konsentrasi, dan kesiapan mental.

Jadwal pelaksanaan dan materi yang disampaikan dalam Pelatihan Kemampuan Komunikasi Bahasa Inggris Sebagai Kesiapan Ekonomi Bagi Siswa PIK R Di SMP Muhammadiyah I Rawabening sebagai berikut:

a. Tanggal Pelaksanan : 26 Oktober- 28 November 2019

b. Tempat Pelaksanaan : SMP Muhammadiyah I Rawabening

c. Waktu Pelaksanaan : Pukul 08.00-10.00 
Tabel 1. Jadwal Kegiatan Pengabdian Masyarakat

Pelatihan Kemampuan Komunikasi Bahasa Inggris Sebagai Kesiapan Ekonomi Bagi Siswa PIK R di SMP Muhammadiyah I Rawabening

\begin{tabular}{|c|c|c|c|}
\hline$\overline{\text { No }}$ & Hari, Tanggal & Pemateri & Materi \\
\hline 1. & $\begin{array}{c}\text { Sabtu, } \\
26 \text { Oktober } 2019\end{array}$ & Hj. Mursilah, ME. & $\begin{array}{c}\text { Penyiapan kehidupan } \\
\text { berkeluarga dari segi } \\
\text { ekonomi }\end{array}$ \\
\hline 2. & $\begin{array}{c}\text { Kamis, } \\
31 \text { Oktober } 2019\end{array}$ & Zulaikah, M.Pd & $\begin{array}{l}\text { Buying and selling } \\
\text { conversation }\end{array}$ \\
\hline 3. & $\begin{array}{c}\text { Sabtu, } \\
2 \text { November } 2019\end{array}$ & Hj. Mursilah, ME. & $\begin{array}{c}\text { Aspek ekonomi } \\
\text { kehidupan berkeluarga }\end{array}$ \\
\hline 4. & $\begin{array}{c}\text { Kamis, } \\
7 \text { November } 2019\end{array}$ & $\begin{array}{l}\text { Hastuti Retno } \\
\text { Kuspiyah, M.Pd }\end{array}$ & Negotiation conversation \\
\hline 5. & $\begin{array}{c}\text { Sabtu, } \\
\text { 9 November } 2019 \\
\end{array}$ & Hj. Mursilah, ME. & Jenis kebutuhan ekonomi \\
\hline 6 & $\begin{array}{c}\text { Kamis, } \\
14 \text { November } 2019\end{array}$ & Zulaikah, M.Pd & $\begin{array}{l}\text { Supply of goods } \\
\text { conversation }\end{array}$ \\
\hline 7 & $\begin{array}{c}\text { Sabtu, } \\
\text { 16 November } 2019\end{array}$ & Hj. Mursilah, ME. & Aset keluarga \\
\hline 8 & $\begin{array}{c}\text { Kamis, } \\
21 \text { November } 2019\end{array}$ & $\begin{array}{l}\text { Hastuti Retno } \\
\text { Kuspiyah, M.Pd }\end{array}$ & $\begin{array}{l}\text { Expressing of Offering } \\
\text { help }\end{array}$ \\
\hline 9 & $\begin{array}{c}\text { Sabtu, } \\
23 \text { November } 2019\end{array}$ & Hj. Mursilah, ME. & Keuangan keluarga \\
\hline 10 & $\begin{array}{c}\text { Kamis, } \\
28 \text { November } 2019\end{array}$ & $\begin{array}{l}\text { Hastuti Retno } \\
\text { Kuspiyah, M.Pd }\end{array}$ & $\begin{array}{l}\text { Expressing Ordering } \\
\text { Service }\end{array}$ \\
\hline
\end{tabular}

Sumber: Data di Lapangan, 2019

\section{Hasil dan Diskusi}

Berdasarkan wawancara, tanya jawab dan pengamatan langsung selama kegiatan pelatihan kemampuan komunikasi bahasa inggris sebagai kesiapan ekonomi pada siswa PIK R di SMP Muhammadiyah I Rawabening, serta hasil dari conversation kegiatan pengabdian pada masyarakat ini memberikan hasil sebagai berikut: 
a. Meningkatnya kemampuan komunikasi bahasa inggris terutama dalam hal vocabularies tentang ekonomi, dengan menerapkan metode silent way.

b. Setelah melakukan proses pelatihan langsung kepada seluruh anggota PIK-R setidaknya bisa memberikan pemahaman bagaimana menyiapkan kerangka ekonomi keluarga disaat mereka sudah tidak duduk dibangku sekolah.

c. Setelah melakukan proses pelatihan, Kegiatan PIK R dan pelatihan kemampuan komunikasi bahasa Inggris dapat membiasakan diri remaja dalam pembentukan karakter positif guna merencanakan masa depan yang lebih baik dan tidak banyak bergantung dengan keadaan namun bisa survive dengan kemampuan distingtif individu.

d. Antusiasme yang sangat tinggi dari para peserta dengan tergugahnya semangat mereka untuk belajar, merancang kreativitas dan menjadi problem solver untuk masalah pendidikannya.

e. Merangsang pengetahuan mereka tentang kemandirian ekonomi melalui komunikasi berbahasa asing, terutama bahasa Inggris.

Hasil pelatihan ini menunjukkan bahwa siswa sangat komunikatif dan mengapresiasi pelatihan tersebut, mengingat bahwa adanya ketertarikan siswa dalam mengikuti pelatihan ini dan atas dasar kesadaran dalam pentingnya kemampuan penerapan bahasa inggris sebagai alat komunikasi diantaranya dalam bidang ekonomi membuat siswa bersemangat dalam mengikuti pelatihan ini.

Adapun dokumentasi kegiatan Pelatihan Kemampuan Komunikasi Bahasa Inggris Sebagai Kesiapan Ekonomi Bagi Siswa PIK R Di SMP Muhammadiyah I Rawabening yang menunjukkan pelaksananaan pelatihan dan proses keberlangsungan komunikasi antar tim pengabdi dengan siswa adalah sebagai berikut. 


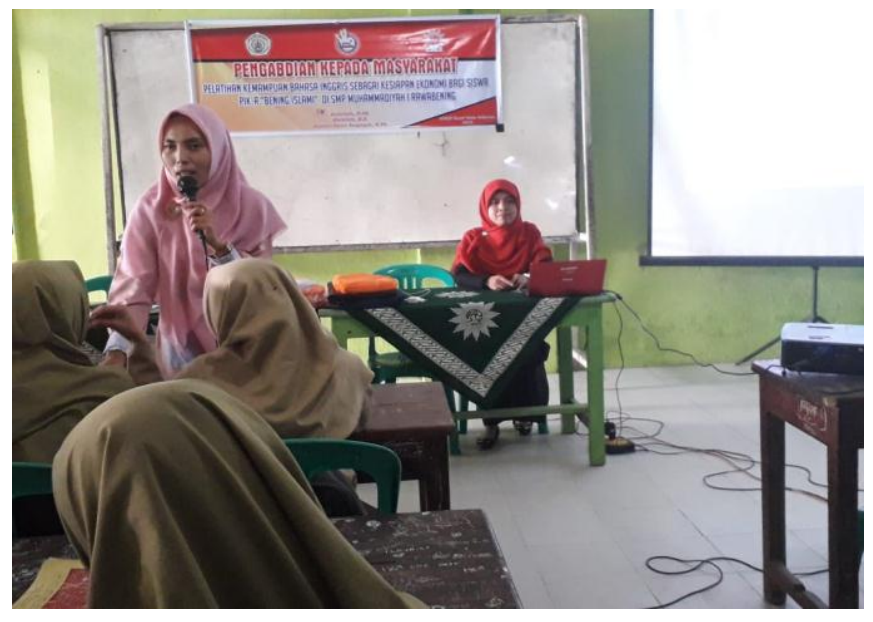

\section{Gambar 3.1 Pelatihan Kemampuan Bahasa Inggris (Sumber: Dokumentasi Pengabdian, 2019)}

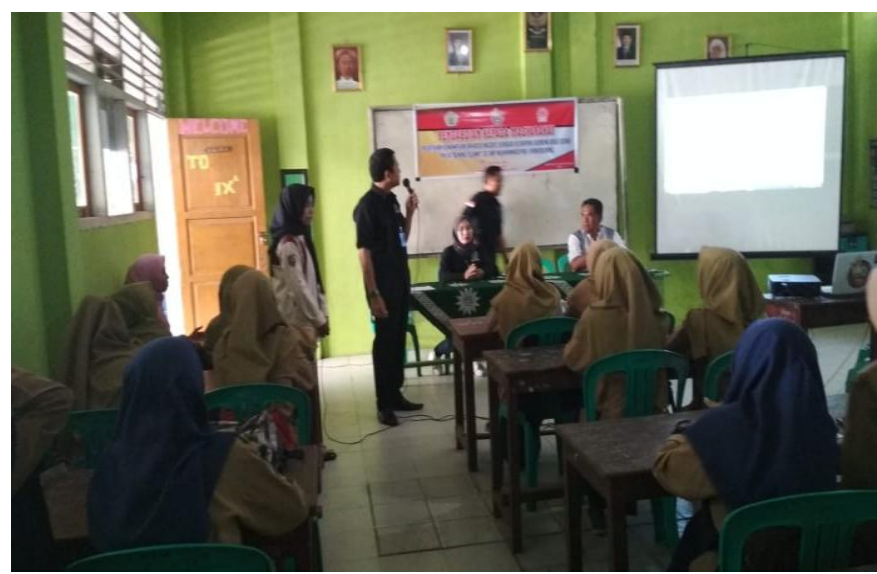

\section{Gambar 3.2 Pelatihan Ekonomi Pada Siswa (Sumber: Dokumentasi Pengabdian, 2019)}

\section{Simpulan}

Kegiatan pengabdian pada masyarakat ini dapat disimpulkan bahwa: Pengetahuan dan komunikasi dalam bahasa Inggris siswa SMP Muhammdiyah I Rawabening menjadi lebih meningkat begitu juga setelah melakukan proses pelatihan, kegiatan PIK R dan pelatihan kemampuan komunikasi bahasa Inggris dapat membiasakan diri remaja dalam pembentukan karakter positif guna merencanakan masa depan yang lebih baik dan tidak banyak bergantung dengan keadaan namun bisa survive dengan kemampuan distingtif individu.

Pelatihan Kemampuan Komunikasi Bahasa Inggris Sebagai Kesiapan Ekonomi Bagi Siswa 


\section{Daftar Referensi}

Chaer, Abdul. 2009. Pengantar Semantik Bahasa Indonesia. Jakarta: Rineka Cipta.

Gattegno, C. 1972. Teaching Foreign Language in Schools The Silent Way, 2 nd ed.NewYork : Educational Solutions.

Hurlock, E.B. 1993. Psikologi perkembangan, Jakarta: Erlangga.

Muadz, Masri dkk. 2016. Penyiapan Kehidupan Berkeluarga bagi Remaja, BKKBN, Jakarta.

Undang-undang Sistem Pendidikan Nasional No 20 Tahun 2003 